\title{
The Level of Psychological Security and its Relationship to the Achievement Motivation Level among the Physically Disabled in Jordan
}

\author{
Naji Minwer AL-Saaydeh ${ }^{1, *}$, Eman Saeed AL-Bourini ${ }^{1}$, Wail Minwer AL-Rabadi ${ }^{1}$ \& Asmaa \\ Abedl Hafez AlJa'afreh ${ }^{1}$ \\ ${ }^{1}$ AL- Balqa Applied University, Jordan \\ *Correspondence: AL- Balqa Applied University, Jordan. E-mail: sahel.3tom@gmail.com
}

Received: July 10, 2017 Accepted: August 2, 2017 Published: September 20, 2017

doi:10.5296/ije.v9i3.11714 URL: https://doi.org/10.5296/ije.v9i3.11714

\begin{abstract}
The study aimed at identifying the Level of Psychological Security and its Relationship to the Achievement Motivation Level among the Physically Disabled in Jordan. In order to achieve the study objectives, the study used the correlative descriptive approach. The study sample consisted of (65) physically disabled were randomly selected from association and center in Irbid governorate in Jordan. The study used two tools; first one is the psychological security scale for Najjar's (2012), and the second one is the achievement motivation scale which was developed by the researchers, which were used after verifying their psychometric properties through validity and reliability in the second semester of 2015/2016.

The results of the study indicated that the levels of psychological security, and achievement motivation among the physically disabled were medium, and the results also showed a positive correlation between psychological security and achievement motivation among the physically disabled.

The study recommends the necessity of holding training and guiding programs to raise the psychological security and achievement motivation levels among the physically disabled in Jordan, and conducting more researches and studies of psychological security and achievement motivation variables among the physically disabled and relating them with other variables such as gender, severity of disability, and type of disability.
\end{abstract}

Key words: Psychological Security, Achievement Motivation, Physically Disabled. 


\section{Introduction}

The concepts of psychology security and achievement motivation are of the issue that received great interest from researchers in the different domains of psychology because of their importance in the life of individuals in general and the disabled in particular. This influences the stability of the individual's attitude toward their aptness to work and production and their positive agreement with the various aspects of life.

Al-Tabrawi (2007) believes that psychological security makes a person feel that their needs are fulfilled and that the basic elements of their life are not exposer to danger. He also argues that the consequences of physical impairment are of the reason why the physically impaired to feel the failing of fulfillment, the shortcoming self-realization and self-confidence, panic, public phobia, dissatisfaction, isolation, inferiority, desperation and frustration

Al-Hareth, \& Ghassan (2006) remarked that it is psychological tranquility and emotionally, circumstances where needs fulfillment is assured rather than endangered, mental security is blended of self-assurance and self-confidence in addition to owned by a safe group.

Regardless of the multiple conditions used to spell it out psychological security, most of them suggest that psychological security is the sensation of tranquility, remoteness from stress and anxiety and disorders, sense of emotional compatibility and the internal health of the average person (Al-Rashaydeh, 2014).

The idea of psychological security is a thorough multi-sided theoretical model that implies basic elements and components that are displayed in self-acceptance, positive interrelations with others and self-reliance in addition to self-environment control, self-development and purposive life (Bishmakh, 2002).

Zahran (2003) adds that many studies stated that psychological security has many properties: psychological security is determined by positive social upbringing, successful social, interaction, social experience and compatible environment. Moreover, the lettered and educated persons are more psychologically secured than the uncultured and illiterate ones. Loyal and obedient children and their parents also enjoy psychological security. Psychological security affects academic achievements and accomplishment in general and leads to creativity.

For the psychological security to be realized, the individual should have self-confidence and self-esteem. They must also develop themselves, admit their shortcomings and imperfection and recognize the reality of facts (Al-Jameel, 2002).

Nonetheless, Abbas (1997) explained that psychological security faces certain threats represented in the familial factors and wrong educational methods which affect growth in different ways in addition to the attachment and separation anxiety.

Lack of psychological security appears among the physically disabled as a reflection of their performance status and behavior which necessitates paying attention to their psychological health. In addition, Haines (2002) argues that the lack of the psychological security feeling reduces the degree of achievement motivation. 
Zuhda, \& Shafrin (2010), assert that the unprotected physically impaired feels neglect and isolation because they notice that their environment is packed with risks and doubts, so they slowly but surely create selfishness and nervousness making them lose the sensation of psychological security and having less any supportive or dependable person nowadays.

Taking this as a starting place, we find that the family has an essential role in revitalizing achievement inspiration as it grows up during youth and a big. Part of it is determined by the parents through their manner of interaction with their children. The achievement motivation among children is influenced by the emotional components provoked by the parents when rewarding their children for their good performance. This increases the high levels of achievement motivation (Abu-Riash, Al-Safi, \& Ammour, 2006).

Achievement Motivation is one of the self-efficacy drives. It is a characteristic of people irrespective of their ages, levels, physical situation and the degree of their disability. This pushes them to challenge, do good job and achieve success. Achievement motivation is defined as: the possibility to coin a target that challenges the individual's capacity and requires placing an achievement plan to realize this goal in the light of quality standards and within a specified period of time with providing an indicator to the system toward the realization of this goal (Abu-Shaqa, 2007: 11).

Singh, Granville, \& Dike (2002) define achievement motivation as the desire that drives a person to act or behave in a certain manner.

Al-Awamleh (2010) draws attention to the factors that affect the level of achievement motivation like success and accomplishment as well as the state of delight expected from success and the wish to realize a positive self-esteem and the elevate and sustain it. Samuel (1997) provides that the only path to learn it is to apply it and develop it signifying the introduction of the individual's mental, mental and behavioral capacities to help them understand themselves and their environment and therefore achieve their goals and utilize their capacities. This is achieved through centering the interest on the existing incidents in conditions of their time and place and providing and repairing cognitive and mental experience in addition to supporting the given individual to identify their own experience and practice it as an effort to create a conception from what is happening. Joining the knowledge to the individual's value, goals and tendencies comes with an impact in the introduction of motivation.

Achievement Motivation, in the educational environment, represents one of the important factors that direct and activate the individual's behavior, their recognition to situations and their interpretation to the behavior of the surrounding people in the different competitive situations, considering the achievement motivation as an energy that drives and stimulates the individual to compete in the situations that demand high levels of challenge to realize and assert themselves and the desire to achieve better life (Al-Sahli, 2015).

The researchers of the present study, through observing lots of educational books and studies, declare that the people of special needs on the whole and the physically handicapped specifically suffer inadequate felling of personal and social security, this is related to the most 
negative bordering attitudes, having less sufficient supporting resources rather than facilitating environmentally friendly hurdles before them which restricts the probability of rivaling others in work, learning, or social activities. Therefore, we find that the level of their self-esteem will not match with their ordinary peers, as the incorrect social values about people with special needs skills and capacities adversely have an effect on their self-esteem and ambitions.

Thus, we find that psychological security and achievement motivation are of the subjects that received the attention of researchers in view of their influence and significance for human behavior. From the studies looked at by the research workers and which treated the two variables found that there is acquired different objectives, methodologies, tools, and results, and these studies include:

The study of Al-Tayyeb (2015) aimed at identifying the adaptive physical and athletic activity and its relationship to achievement motivation among the physically disabled. The study adopted the descriptive correlative analytical approach and the randomly selected samples contained (60) physically disabled persons from three clubs and three centers in the state of Algeria. The sample was divided into two groups one of which was practicing physical athletic activities while the second was not engaged in such activities. The study attempted to recognize the differences between the two groups each of which consisted of (30) physically disabled persons. The study used the achievement motivation scale of AlAzraq (2000)/ the results showed that the level of achievement motivation among the physically disabled who practice athletic activities was higher and better than the level of the same among the physically disabled who do not practice said activities. The results also indicated the presence of direct relation between practicing these activities and the level of achievement motivation.

Eleiwi (2012) conducted a study to recognize the relationship between psychological hardness and achievement motivation among athletes with physical disability in the West Bank. The analysis used the deceptive correlative strategy and the test contains (86) physically handicapped athletes. The study used the psychological hardness scale of (Suliman, \& Abdul-wahab, 2005), and the athletic achievement motivation scale of (Allawi ,1998). The results indicated that the level of each of the psychological hardness and the achievement motivation was high among the physically disabled. The results also revealed statistically significant differences in achievement motivation due to the variables of (gender, type of game, years of practice) in favor of the males. There also appeared to be a direct relationship between psychological hardness and achievement motivations in the dimension of (success achievement motive) as well as a negative relationship between them concerning the (failure avoidance motive). The results also showed the presence of a negative relationship between the success achievement motive and the failure avoidance motive.

The study of Al-Najjar (2012) identified the impact of a guiding program in the development of psychological security among the physically disabled. The analysis used the semiexperimental strategy and the test contains (24) disabled specific sent out on two groupings: The control group which contains (12) handicapped person and the experimental group which 
counted (12) impaired person. The results disclosed the lack of statistically significant dissimilarities among the subconscious security sizes means between your experimental and control groupings in the pre-test dimension. It also discovered the occurrence of statistically significant distinctions for the experimental group in the post-test way of measuring of the internal security dimensions aside from the ambition dimensions that was statistically insignificant.

The study of Zuhda, \& Shafrin (2010) aimed at identifying the state of social isolation resulted from the physical injury among the physically disabled. The study implemented the descriptive analytical way, where the analysis sample contains (6) physically disabled people/ the analysis remarked that a lot of the physically handicapped prefer remoteness and isolation from the encompassing society participants, especially their normal peers, for their lack of internal and sociable security and the lack of appropriate treatment and attention from others.

Al-Hilou, \& Nabeel (2007) conducted a study which revealed the most important and distinctive auditory, visual and physical features of the disabled personality in the light of some variables which are (gender, type of disability, age and academic qualification). The study followed the descriptive analytical way and the test which was picked following purposive method contains (498) disabled people from both genders from (18) nationwide organizations from different governorates of Gaza. The analysis sued an instrument to gauge the auditory, aesthetic and physical distinctive top features of the handicapped. The results confirmed that the main attributes of the three disabilities were recognized by the spiritual and social dynamics as well as the feature of freedom. They also mentioned the non-existence of statistically significant distinctions among the list of three disabilities all together in the mental dimension attributes. The feature of regression occupied the first ranking as the feature of security took the previous rank. There have been also statistically significant distinctions among the reading impaired in the emotional, religious and cultural dimensions and only the guys and statistically significant dissimilarities among the bodily handicapped in the aspect of independence and only the males. For the varying of the sort of disability, the reading impaired category was recognized by the public accept set alongside the other categories. There have been no statistically significant dissimilarities regarding the other features one of the three disabilities credited to the sort of impairment. The results described the occurrence of statistically significant distinctions in the full total credit score of the academics qualification variable among the list of three disabilities and only the university level and above.

Turner, \& Turner (2004) conducted a study that aimed at identifying the psychological effects resulted from the injury of physical disability. The study used the survey analytical method and the study sample consisted of (556) physically disabled individuals. The study applied the scale of psychological pressure and depression among the physically disabled. The results indicated that the rate of the psychological pressure among the physically disabled was high especially during the period that follows the injury at the rate of $\% 30$. 


\section{MInstitute"}

\section{Method and Procedures}

\subsection{Questions of the Study}

The study presented the following questions:

First question: What is the level of psychological security among the physically disabled in Jordan?

Second question: What is the level of achievement motivation among the physically disabled in Jordan?

Third question: Is there a statistically significant correlation at $(a \leq 0.05)$ between the level of psychological security and the level of achievement motivation among the physically disabled in Jordan?

\subsection{Objectives of the Study}

The study aimed at identifying the following:

- The levels of psychological security and achievement motivation among the physically disabled in Jordan.

- The level and type of relationship between the levels of psychological security and achievement motivation among the physically disabled in Jordan.

\subsection{Importance of the Study}

The importance of the study appears in the theoretical and applied aspects as follows:

\section{The theoretical aspect:}

- The study will display the theoretical educational literature and the previous studies related to the study variables.

- Determining the critical need to the sensation of psychological security in shaping the personality of the literally disabled and helping their soul of persistence and accomplishment.

\section{The applied aspect:}

- The results which will be produced by the study may help the people of concern and the decision makers in placing the necessary strategies to improve the psychological condition of the physically disabled and urge them toward the spirit of initiative and achievement though providing them with the proper circumstances as well as training and guiding them to realize psychological security.

- The results will also provide the researchers with a measurement instrument which was developed through high psychometric properties to be utilized when conducting further researches about achievement motivation. 


\subsection{Conceptual and Procedural Terms}

Psychological Security: "The disabled individual's feeling that they are liked and accepted by others, have their standing among them and that their environment is friendly and free from frustration, danger and threat" (Al-Rashaideh, 2014). Procedurally, it is defined by the sore attained by the physically disabled on the psychological security scale used for the purpose of the current study. It is procedurally, it is defined by the sore attained by the physically disabled on the psychological security scale used for the purpose of the current study.

Achievement Motivation: It is "A characteristic of human beings irrespective of their ages or standards. This motive is represented in the desire of performing a good job successfully. Achievement motivation has a multiple dimensions like persistence, ambition and sought goal to mention but a few" (Abu-Jado, 2003). Procedurally, it is defined as the score which the physically disabled will attain on the achievement motivation scale used for the purpose of the current study.

The Physically Disabled: "They are those who sidestep off the normal individuals in terms of the sensual and kinetic aspects and are unable to use their organic capacities to a degree where they require special medical, rehabilitating, educational, psychological and social services" (Al-Tayeb, 2015). Procedurally, they are the physically disabled associated with the special education centers in Irbid governorate in the first semester of the academic year $2014 / 2015$.

\subsection{Limitation of the Study}

The chronological Limitations: The study was conducted in the second semester of the year 2015/2016.

The Spatial Limitations: the application of the study was restricted to Al-Shamal Association for People with Special Needs, and Al-Nahda Center for Motor Disability Challenges in Irbid governorate.

The Human Limitations: the study was confined to the individuals associated with the association and center counting (65) physically disabled persons.

The Objective Limitation: This study is identified by its two instruments and their psychometric and methodological properties.

\section{Population and Sample of the Study:}

\subsection{Population of the Study}

The population of the study consists of all associates with Al-Shamal Association for People with Special Needs and Al-Nahda Center for Motor Disability Challenges in Irbid governorate where the members of both association and center reached at (85) physically disabled people. 


\section{Ml Macrothink}

Sample of the study: The study sample consisted (65) physically disabled person were randomly selected from each of association and center in Irbid governorate in Jordan.

\subsection{Research Instruments}

\section{First: Psychological Security Scale:}

The researchers used the psychological security scale prepared by Al-Najjar (2012) as it is for the physically disabled in Palestine to fit and harmonize the Palestinian environment with that of the Jordanian. The scale consisted of (60) items for each of the following domains: Selfacceptance, reassurance, independence, social acceptance, faith and ambition. The domains contained positive items and negative items graded according to the five-step progression (always, often, sometimes, rarely, never). One mark was given to the alternative never, two marks to rarely, three marks to sometimes, four marks to often and five marks to always. This is in case of the positive items and the weights are reversed in the case of negative items.

\section{Validity of the Scale:}

The validity of the psychological security scale of this study was calculated through the validity of the internal consistency between the domains and the total score of the scale on an exploratory sample of (20) disabled persons from outside the original sample. Table No. (1) Shows the results.

Table 1. Values of Correlation Coefficient between the Domains and the Total Score

\begin{tabular}{lcccccc}
\hline Domains & $\begin{array}{c}\text { Self-Accepta } \\
\text { nce }\end{array}$ & $\begin{array}{c}\text { Reassuranc } \\
\mathbf{e}\end{array}$ & Independence & $\begin{array}{c}\text { Social } \\
\text { Acceptance }\end{array}$ & Faith & Ambition \\
\hline $\begin{array}{l}\text { correlation } \\
\text { coefficient } \\
\text { values }\end{array}$ & $0,78^{* *}$ & $0,85^{* *}$ & $0,84^{* *}$ & $0,86^{* *}$ & $0,83^{* *}$ & $0,80^{* * *}$ \\
\hline
\end{tabular}

** Significant at $(\mathbf{a}=\mathbf{0 . 0 1})$

The previous table shows that all the correlation coefficients are significant at $(\mathrm{a}=0.01)$ which indicates that the scale enjoys a validity degree sufficient to the purpose of the study.

\section{Reliability of the Scale}

To verify the validity of the scale, two methods were used. The first: reapplying the scale on an exploratory sample of (20) disabled individuals from outside the study sample whereby the first application of validity were adopted as first application, and two weeks later the second application was arranged. Pearson correlation coefficient was used to extract the reliability where the total reliability coefficient reached at $(0.80)$ which is good for the purpose of the study. The second: Using Cronbach's test for the psychological security scale wherein the Cronbach's Alpha values for the instrument as a whole was (0.84) which is 
suitable value for the purpose of the study.

\section{Second: The Achievement Motivation Scale:}

The scale was prepared and developed by the researchers after examining the psychological and educational literature and reviewing the scales used in the previous studies and researchers like the studies of Al-Sahli (2015), Eleiwi (2012), Abu-Shaqa (2007), Al-Muteiri (2007); Vermeer, Monique \& Greer (2001) and Gottfried (2000).

The scale's items counted (23) positive and negative items and the responses ranged among five levels (very low, low, average, high, very high). The weights of the positive items are granted as follows: (one mark for the alternative very low, two marks for the alternative low, three marks for average, four marks for high, five marks for very high). The weights are reversed fir the negative items.

\section{Validity of the Scale:}

The construct validity was drawn out through applying the study instrument on (20) physically disabled as on exploratory sample from outside the original sample and the correlation coefficient of the internal consistency validity between the items and the scale as a whole was extracted. Table (2) explains the results.

Table 2. The correlation coefficient of the internal consistency between the items and the scale as a whole

\begin{tabular}{cccccccccc}
\hline $\begin{array}{c}\text { Item } \\
\text { No. }\end{array}$ & $\begin{array}{c}\text { Correlation } \\
\text { Coefficient }\end{array}$ & $\begin{array}{c}\text { Item } \\
\text { No. }\end{array}$ & $\begin{array}{c}\text { Correlation } \\
\text { Coefficient }\end{array}$ & $\begin{array}{c}\text { Item } \\
\text { No. }\end{array}$ & $\begin{array}{c}\text { Correlation } \\
\text { Coefficient }\end{array}$ & $\begin{array}{c}\text { Item } \\
\text { No. }\end{array}$ & $\begin{array}{c}\text { Correlation } \\
\text { Coefficient }\end{array}$ & $\begin{array}{c}\text { Item } \\
\text { No. }\end{array}$ & $\begin{array}{c}\text { Correlation } \\
\text { Coefficient }\end{array}$ \\
\hline 1 & $* * 0,66$ & 6 & $* * 0,70$ & 11 & $* * 0,78$ & 16 & $* * 0,79$ & 21 & $* * 0,84$ \\
2 & $* * 0,72$ & 7 & $* * 0,71$ & 12 & $* * 0,91$ & 17 & $* * 0,69$ & 22 & $* * 0,92$ \\
3 & $* * 0,64$ & 8 & $* * 0,62$ & 13 & $* * 0,78$ & 18 & $* * 0,70$ & 23 & $* * 0,77$ \\
4 & $* * 0,78$ & 9 & $* * 0,66$ & 14 & $* * 0,80$ & 19 & $* * 0,72$ & & \\
5 & $* * 0,74$ & 10 & $* * 0,90$ & 15 & $* * 0,69$ & 20 & $* * 0,84$ & & \\
\hline
\end{tabular}

\footnotetext{
$* *$ Statistically significant at $(\mathbf{a}=\mathbf{0 . 0 1})$
}

The previous table shows that the correlation coefficients between the item and the total score of the scale ranged between $(0.62-0.92)$ which are all statistically significant at $(a=0.01)$ which indicates that the scale enjoys a sufficient validity degree for the purpose of the study.

\section{Reliability of the Scale:}

To verify the validity of the scale, two methods were used. The first: reapplying the scale on an exploratory sample of (20) disabled individuals from outside the study sample whereby the first application of validity were adopted as first application, and two weeks later the second application was arranged. Pearson correlation coefficient was used to extract the reliability where the total reliability coefficient reached at $(0.89)$ which is good for the purpose of the study. The second: Using Cronbach's test for the psychological security scale wherein the Cronbach's Alpha values for the instrument as a whole was (0.93) which is 


\section{Macrothink}

suitable value for the purpose of the study.

\subsection{Statistical Standard}

The study used the five-step grading for both scales, and accordingly, the modified range of the individual's responses to each scale was according to the following equation:

Maximum value of response alternatives- minimum value of response alternatives divided by number of levels that is:

$\frac{(5-1)}{3}=\frac{4}{3}=1.33$ and this value equals the category length.

The judgment on the resulting value is shown in the following table No. (3).

Table 3. The standard used to judge the results of the psychological security and achievement motivation scales

\begin{tabular}{ccc}
\hline No. & Standard & Range \\
\hline $\mathbf{1}$ & high level & $(3,68-5)$ \\
$\mathbf{2}$ & medium level & $(2,34-3,67)$ \\
$\mathbf{3}$ & low level & $(1-2,33)$ \\
\hline
\end{tabular}

\subsection{Statistical Treatment}

The researcher used the following statistical treatments in data analysis: Arithmetic means, standard deviations, Pearson's correlation coefficients and Cronbach's Alpha methods.

\section{Results and Discussions of the Study}

3.1 Results and discussions of the first question which is: "What is the level of psychological security among the physically disabled in Jordan?"

To answer this question, the arithmetic means and standard deviations were extracted for all the psychological security dimensions among the physically disabled. Table (4) shows the results.

The previous table shows that the arithmetic means of the psychological security dimensions among the physically disabled ranged between (3.16-3.73). The dimension of ambition took the first rank with an arithmetic mean of (3.73) and a standard deviation of (0.847) while the last rank was occupied by the dimension of self-acceptance with an arithmetic mean of (3.16) and a standard deviation of (1.270) whereupon the total mean of the psychological security was (3.26) with a standard deviation of (1.161). 
Table 4. The Arithmetic Means and Standard Deviations of the Psychological Security Dimensions

\begin{tabular}{ccccc}
\hline Rank & Dimension & Arithmetic Mean & Standard Deviation & Level \\
\hline 6 & self-acceptance & 3.16 & 1.270 & medium \\
4 & reassurance & 3.37 & 1.207 & medium \\
3 & faith & 3.48 & 1.480 & medium \\
1 & ambition & 3.73 & 0.847 & high \\
2 & independence & 3.59 & 1.043 & medium \\
5 & social & 3.21 & 1.119 & medium \\
& acceptance & $\mathbf{3 . 2 6}$ & $\mathbf{1 . 1 6 1}$ & medium \\
\hline
\end{tabular}

The first question's results indicate that the level of psychological security among the physically disabled was medium where the total arithmetic mean was (3.23). The dimension of ambition came in the first rank with a high score as the arithmetic mean reached at (3.73), followed by the dimension of independence with an arithmetic mean of (3.59) then the dimension of faith with an arithmetic mean (3.48) then the reassurance dimension with an arithmetic mean (3.73) then social acceptance with (3.21) and finally self-acceptance with an arithmetic mean of (3.16).

This result can be explained in that the physically disabled lives in a world limited by the circumstances of their disability. They have to achieve a level of psychological security and reassurance with the social surrounding which is mostly described with various attitudes and reactions towards physical disability and the disabled in general. Moreover, the physically disabled, despite the pressing circumstances and incidents, seek to realize their ambitions. The high moral spirit with which they challenge their disability and their insistence to attain their desired goals plays a great role in achieving high levels of ambition and this was clear from the results of the study where ambition took the first rank while the dimension of independence came in the second rank which means that the physically disabled are struggling to achieve independence and self-dependence, and that they are able to find solutions for their problem with no need to others. This gives the opportunity to lead their life affairs independently without being a burden on other people. The dimension of faith came in the third rank indicating the presence of deep sense of faith among them. They believe in fate and do not blame their bad luck. This dimension makes them feel security and tranquility and deal with others through their points of strength rather than weakness. As for reassurance, it is noticeable that the physically disabled do not enjoy high level of reassurance. This because of the way they are seen by others, the non-availability of supporting sources and the scarcity of their chances in life which makes them anxious for their future. Concerning the dimension of social acceptance, the physically disabled feel themselves unable to create positive social interactions because of the limitation of movements, the negative attitudes toward the disabled in general and viewing them through their points of weakness and not the points of strength. Therefore, we see them inactive in the social occasions and activities and unable to perform their social roles properly. The dimension of self-acceptance took the last rank. This means that the disability affects the individual as much meaning as it has in the psych of the 
disabled. The disabled in general reject their disability. They feel inferior and different compared to others. This contributes in the decline of their self-concept and minimizes their efficiency, achievement and attitude in life. This result differed from the results of the study of Al-Najjar (2012) which pointed out that the level of psychological security among the physically disabled was high. It also differed from the study of Al-Hilou, \& Nabeel (2007) the results of which showed that the dimension of security and reassurance occupied the last rank.

3.2 Results and discussion of the second question which is: "What is the level of achievement motivation among the physically disabled in Jordan?"

To answer this question, the arithmetic means and standard deviations were extracted for all the items which represent the achievement motivation level among the physically disabled in Jordan. Table (5) shows the results.

Table 5. The arithmetic means and standard deviations of the level of achievement motivation

\begin{tabular}{|c|c|c|c|c|c|}
\hline No & $\begin{array}{l}\text { the item in } \\
\text { the scale }\end{array}$ & $\begin{array}{l}\text { the descending order of the item } \\
\text { according to means }\end{array}$ & $\begin{array}{l}\text { arithmetic } \\
\text { mean }\end{array}$ & $\begin{array}{l}\text { standard } \\
\text { deviation }\end{array}$ & level \\
\hline 1 & 21 & $\begin{array}{l}\text { I enjoy performing my studying } \\
\text { works. }\end{array}$ & 4.27 & 0.664 & high \\
\hline 2 & 11 & $\begin{array}{l}\text { I escape my obligations and } \\
\text { responsibilities because of my } \\
\text { disability. }\end{array}$ & 4.16 & 0.368 & high \\
\hline 3 & 17 & $\begin{array}{l}\text { Success comes as a result of luck } \\
\text { and chance. }\end{array}$ & 4.04 & 0.816 & high \\
\hline 4 & 10 & $\begin{array}{l}\text { I get annoyed from my bad } \\
\text { performance to physical tasks. }\end{array}$ & 3.82 & 0.757 & high \\
\hline 5 & 19 & $\begin{array}{l}\text { I prefer the tasks which do not } \\
\text { require physical efforts. }\end{array}$ & 3.70 & 1.219 & high \\
\hline 6 & 3 & I avoid troubles. & 3.64 & 1.210 & medium \\
\hline 7 & 13 & I help others seriously and carefully. & 3.61 & 1.154 & medium \\
\hline 8 & 20 & $\begin{array}{l}\text { I do not like to be responsible for } \\
\text { others. }\end{array}$ & 3.60 & 0.899 & medium \\
\hline 9 & 16 & $\begin{array}{l}\text { I exert great efforts to attain } \\
\text { excellence. }\end{array}$ & 3.51 & 1.367 & medium \\
\hline 10 & 18 & My problem is that I am ambitious. & 3.51 & 1.738 & medium \\
\hline 11 & 4 & $\begin{array}{l}\text { I prefer studying to enjoying a } \\
\text { picnic. }\end{array}$ & 3.50 & 1.611 & medium \\
\hline 12 & 14 & $\begin{array}{l}\text { I am interested in knowing about the } \\
\text { lives of excellent disabled. }\end{array}$ & 3.47 & 0.658 & medium \\
\hline 13 & 1 & The secret of my excellence is my & 3.44 & 1.250 & medium \\
\hline
\end{tabular}




\begin{tabular}{|c|c|c|c|c|c|}
\hline No & $\begin{array}{l}\text { the item in } \\
\text { the scale }\end{array}$ & $\begin{array}{l}\text { the descending order of the item } \\
\text { according to means }\end{array}$ & $\begin{array}{l}\text { arithmetic } \\
\text { mean }\end{array}$ & $\begin{array}{l}\text { standard } \\
\text { deviation }\end{array}$ & level \\
\hline 14 & 23 & $\begin{array}{l}\text { competition with others. } \\
\text { I prefer the tasks which require high } \\
\text { intellectual skills. }\end{array}$ & 3.38 & 1.680 & medium \\
\hline 15 & 9 & I highly master my tasks. & 3.37 & 1.125 & medium \\
\hline 16 & 12 & $\begin{array}{l}\text { I do my duties whatever they cost } \\
\text { me. }\end{array}$ & 3.36 & 1.667 & medium \\
\hline 17 & 2 & $\begin{array}{l}\text { I strive for developing the method } \\
\text { of my studying. }\end{array}$ & 3.32 & 1.420 & medium \\
\hline 18 & 6 & $\begin{array}{l}\text { Days pass without realizing any } \\
\text { achievement. }\end{array}$ & 3.27 & 1.355 & medium \\
\hline 19 & 8 & $\begin{array}{l}\text { I avoid doing the tasks that require } \\
\text { movement. }\end{array}$ & 3.21 & 0.935 & medium \\
\hline 20 & 5 & $\begin{array}{l}\text { My problem lies in my permanent } \\
\text { laziness. }\end{array}$ & 3.20 & 1.463 & medium \\
\hline 21 & 7 & $\begin{array}{l}\text { I think and plan a lot before starting } \\
\text { work. }\end{array}$ & 3.18 & 1.480 & medium \\
\hline 22 & 15 & $\begin{array}{l}\text { I seek to be distinguished among my } \\
\text { peers. }\end{array}$ & 3.15 & 1.904 & medium \\
\hline \multirow[t]{2}{*}{23} & 22 & $\begin{array}{l}\text { Failure vexes me when performing } \\
\text { my tasks. }\end{array}$ & 2.46 & 1.666 & low \\
\hline & & total & 3.49 & 1.235 & medium \\
\hline
\end{tabular}

The previous table shows that the arithmetic means of the items of the achievement motivation level among the physically disabled in Jordan through their own perspective ranged between (2.52- 4.06) where that total of this dimension's items reached at (3.49) with a standard deviation of (1.235). The results of the second question point out that the achievement motivation level among the physically disabled in Jordan was medium. This result is attributed to the lack of high expectations of success among the physically disabled students and their surroundings which negatively affected on the level of their achievement motivation. Bounded movement creates many problems for the physically disabled on both the psychological and social aspects, in addition to the high unemployment among them which limits the value of their achievement drive and their effective tendency to life. Adding to that, the lack of the safe infrastructure that contributes in realizing their achievements and facilitating their free movement such as the special passages to laboratories, libraries and theaters... etc. Moreover, there is the inferior outlook from society toward the disabled. The limited attention paid by the governmental organization to this category of society and transgressing their rights in some occasions. All this contributes in dropping the level of achievement motivation among individuals. The results of the present study differs from the studies of Eleiwi (2012), Vermeer, et al, 2001) and Al-Tayeb (2015) whose results revealed that the level of achievement motivation among the physically disabled was high. 
3.3 Results and discussion of the third question which is: "Is there a statistically significant correlation at $(\alpha \leq 0.05)$ between psychological security and achievement motivation among the physically disabled in Jordan?"

To explore the presence of a correlation between psychological security and achievement motivation among the physically disabled in Jordan, the correlation coefficients (Pearson) were calculated. Table (6) shows the results.

Table 6. The correlation coefficients (Pearson) between psychological security and achievement motivation

\begin{tabular}{ccc}
\hline & \multicolumn{2}{c}{ Achievement Motivation } \\
\cline { 2 - 3 } Psychological Security & Level & Sig \\
\hline self-acceptance & $* 0.26$ & 0.021 \\
reassurance & $* * 0.32$ & 0.000 \\
faith & $* * 0.41$ & 0.000 \\
ambition & $* * 0.37$ & 0.000 \\
independence & $* 0.29$ & 0.031 \\
social acceptance & $* * 0.35$ & 0.000 \\
total score & $* * \mathbf{0 . 5 3}$ & $\mathbf{0 . 0 0 0}$ \\
\hline
\end{tabular}

** Correlation is significant at $(\mathrm{a}=0.01)$

* Correlation is significant at $(\mathrm{a}=0.05)$

The previous table shows the existence of a positive correlation between psychological security and achievement motivation among the physically disabled. Pearson's correlation coefficient between the total score of psychological security and the total score of achievement motivation reached at $(0.53)$ where Pearson's correlation coefficients ranged between $(0.26-0.41)$ and all the coefficients are statistically significant.

The results of the third question indicate the presence of a positive correlation between the psychological security and the achievement motivation among the physically disabled at the significance level. This indicates the presence of a direct relationship between psychological security and achievement motivation. That is the higher the psychological security level was the more increased was the achievement motivation among the physically disabled and vice versa. This result confirms that the total arithmetic means of the psychological security and achievement motivation among the physically disabled were of medium degree. The feeling of the physically disabled of security and reassurance, the acceptance of their disability, working to limit the restrictions that confine their free interaction with others and improving the quality of the services presented to them will positively reflect on the level of their ambition and achievement leading them to become effective and productive members who contribute in the wheel of production and development in society. The result of this study agrees with what the study of Haines (2002) in that the lack of psychological security leads to the decline of achievement motivation. 


\section{Conclusion}

The study aimed at identifying the Level of Psychological Security and its Relationship to the Achievement Motivation Level among the Physically Disabled in Jordan.

Study results indicate that the level of psychological security among the physically disabled was medium, and the achievement motivation level among the physically disabled in Jordan was medium. The results also indicate that there is a positive correlation between the psychological security and the achievement motivation among the physically disabled.

\section{Recommendations}

Based on the study results, the researchers recommend the following:

- Holding workshops and lectures for the families of the physically disabled and the institutions to which they belong in order to provide them with the knowledge that will reflect upon their behavior with the disabled.

- Preparing training and guiding programs to raise the level of psychological security and achievement motivation among the physically disabled.

- Investigating psychological security and achievement motivation among the physically disabled together with other variables like gender, intensity of disability and the type of disability... etc.

- The necessity of appreciating their achievements by the surrounding environment which will positively reflect upon their self-esteem.

\section{References}

Abu Jado, Saleh. (2003). Educational psychology ( $3^{\text {rd }}$ ed.). Dar Al-Maseerah for publishing and distribution, Amman, Jordan.

Abu Riash, Hussein; Al-Safi, Abdul-Kareem; \& Ammour, Umaimah. (2006). Motivation and Emotional Intelligence ( $1^{\text {st }}$ ed.). Dar Al-Fikr for printing and publishing, Amman, Jordan.

Abu Shaqa, Sa'dah (2007). Achievement Motivation (1 ${ }^{\text {st }}$ ed.). Al-Nahda Al-Misriyah Library, Cairo, Egypt.

Al-Awamleh, Habes (2010). Motivation ( $1^{\text {st }}$ ed.). Al-Ahliah for publishing and distribution, Amman, Jordan.

Al-Hareth, Abdul-Hameed \& Ghassan, Hussein (2006). Security Psychology(1 ${ }^{\text {st }}$ ed.). Arab House for Sciences, Beirut, Lebanon.

Al-Jameel, Ridwan (2002). Psychological Health(1 ${ }^{\text {st }}$ ed.). Dar Al-Masirah for publishing, Amman, Jordan. 
Al-Najjar, Yahya. (2012). The effectiveness of a guiding program in the development of psychological security among the physically disabled. Journal of Islamic University for educational and psychological studies, 20(1), 557-594.

Al-Rashaideh, Ibrahim (2014). Psychological security and its relationship to self-efficiency among the first secondary grade students in Souther Shona governorate. Unpublished Master thesis, Al-Balqa Applied University, Al-Salt, Jordan.

Al-Sahli, Abdul-Majeed. (20015). Cognitive features and their relationship with achievement motivation in the intermediate stage in Tabuk. unpublished Master thesis, Al-Balqa Applied University, Al-Salt, Jordan.

Al-Tayeb, Firm. (2015). Practicing adaptive physical and athletic activity and its relationship with achievement motivation among the physically disabled. Journal of the Sciences and Techniques of Physical Athletic Activity, University of Algeria, 3(9), 139-148.

Eleiwi, Mohammed. (2012). The relationship between psychological hardness and achievement motivation among the physically disabled athletes in the West Ban. unpublished Master Thesis, Al-Najah University, Palestine.

Gottfried, A. (2000). Academic Intrinsic Motivation in Young Elementary School Children. Journal of Educational Psychology, 82(3), 55-85.

Haines, J. (2002). Multilevel Modeling of Aircraft Noise on Performance Tests in Schools. Airport London Heathrow. (CDROM). J-Epidemic-Community-Health, 5(2), 23-45.

Samuel. B. (1997). Motivation in Education Academic Pares. New York. To San Francisco.

Singh, K., Granville, M., \& Dike, S. (2002). Mathematics and science Achievement: effects of motivation, interest, and academic engagement. Journal of Educational Research, 95(6), 323. https://doi.org/10.1080/00220670209596607

Turner, J., \& Turner, R. (2004). Physical Disability, Unemployment, and Mental Health. Rehabilitation Psychology, 29(49) 241-249. https://doi.org/10.1037/0090-5550.49.3.241

Vermeer, J., Monique, M., \& Greer, D. (2001). Motivational and Gender Differences: sixth Grade student Mathematical problem solving Behavior. Journal of Educational Psychology, 92(2), 300-313.

Zahran, Hamed. (2003). Studies in Psychological Health and psychological guidance. Books World for publishing, Cairo, Egypt.

Zuhda, H., \& Shafrin, A. (2010). Isolation Willingness of Disabled Person to Integrate With its Community in the Context of Relationship after Disabled due to Accidents. Presidia Social and Behavioral Sciences, 1(6), 274-281. 


\section{Copyright Disclaimer}

Copyright for this article is retained by the author(s), with first publication rights granted to the journal.

This is an open-access article distributed under the terms and conditions of the Creative Commons Attribution license (http://creativecommons.org/licenses/by/3.0/). 